\title{
COVID-19 Pandemic Response and Faculty Career Equity
}

\section{Dr. Shawna Vican, University of Delaware}

Shawna Vican is an Assistant Professor of Sociology and Criminal Justice at the University of Delaware. She received her Ph.D. in Sociology from Harvard University. An organizational sociologist, Dr. Vican investigates the adoption and implementation of new employment practices and corporate social behaviors. Across her research, Dr. Vican explores how organizational policies and practices, managerial behavior, and workplace culture shape individual career outcomes as well as broader patterns of labor market inequality. Her current research includes a qualitative study of corporate diversity management strategies and a series of mixed-methods projects on diversity in the academic workforce.

\section{Dr. Robin Andreasen, University of Delaware}

Robin O. Andreasen (Ph.D. University of Wisconsin-Madison) is Professor of Cognitive Science. She earned her $\mathrm{PhD}$ in philosophy and specializes in philosophy of science, philosophy of social science, and in science and policy. A race and gender scholar, Dr. Andreasen is research director and co-PI for UD's ADVANCE-IT grant.

\section{Dr. Heather Doty, University of Delaware}

Heather Doty is an associate professor of mechanical engineering at the University of Delaware (UD). Dr. Doty teaches undergraduate courses in thermodynamics, statics, and dynamics, and conducts research on gender in the academic STEM workforce. She is co-PI on UD's NSF ADVANCE Institutional Transformation grant, which aims to recruit, retain, and advance women STEM faculty at UD. Dr. Doty is faculty advisor to UD's Women in Engineering Graduate Student steering committee.

\section{Dr. L. Pamela Cook, University of Delaware}

Pam Cook is Unidel Professor of Mathematical Sciences at the University of Delaware (UD). Her research interest is in applied mathematics modeling and simulation, particularly of complex, viscoelastic, fluids. She is PI on the University of Delaware NSF ADVANCE IT grant to improve the representation and leadership opportunities of women among the STEM faculty at UD. 


\title{
COVID-19 Pandemic Response and Faculty Career Equity
}

\begin{abstract}
This evidence-based practice paper will address the impact of the COVID-19 pandemic on faculty careers, offering a range of strategies higher education institutions, including engineering schools and departments, may adopt to support faculty and promote equity. Emergent research has documented immediate impacts of the pandemic across all elements of faculty work, including research (e.g. loss of access to labs and field sites), teaching (e.g. shifts to remote or hybrid instruction), and service (e.g. increased student mentoring). At the same time, faculty are differentially impacted by these challenges, with the pandemic expected to amplify longstanding inequities in career progression for women and faculty of color. In this paper, we connect the broader literature on bias and inequity in faculty career progression to more recent work specific to the pandemic, describing how these literatures informed our initial steps to respond to COVID-19 at University of Delaware. After describing our response to-date, we outline emergent challenges and strategies to improve policy implementation. We conclude by suggesting ways in which universities can continue to support faculty career development over the coming years, ensuring that pandemic impacts do not undermine progress towards gender and racial equity in faculty careers. Our preference is for this paper be presented in a traditional lecture format.
\end{abstract}

\section{Introduction}

As we approach one year since universities across the United States began to shift operations and curtail on-campus activities in response to the COVID-19 pandemic, an emerging literature has documented the effects of the pandemic on faculty research, teaching, and service roles. University administrators and those involved in faculty development must consider impacts to faculty achievement, as it is clear the pandemic has the potential to cause long-term negative repercussions on faculty career progression. The nature of the pandemic is such that effects on research, teaching, and service will not be felt equally by all faculty, with women and faculty of color potentially facing the most adverse impacts. Thus, it is imperative that universities ensure their pandemic responses, including changes to promotion and tenure policies, take into account variation in faculty experience and remain attuned to possible bias or inequity that may be amplified post-pandemic.

In this paper, we discuss the response to COVID-19 impacts on faculty careers at the University of Delaware (UD). We begin by describing how the emergent research on pandemic effects on faculty research, teaching, and service, as well as the broader literature on gender and racial barriers in faculty career advancement, informed our initial steps to respond to COVID-19 at UD. Our approach includes adopting new policies (e.g. tenure clock extensions) and developing resources for faculty and evaluators (e.g. guidance on writing COVID impact statements). We next discuss emergent challenges as well as implementation strategies, including working with campus stakeholders, promoting awareness of policies, and adapting existing programming targeting recruiting, retaining, and promoting faculty from underrepresented groups. We conclude by offering guidance for how institutions can remain attentive to COVID-19 impacts on faculty careers in the coming years, with a focus on ongoing evaluation of new policies and programming, and institutional research to monitor equity. 


\section{Pandemic Impacts on Faculty Careers}

In early 2020, as COVID-19 cases spread across the United States, university administrators began to plan institutional responses. While the full scope of the pandemic was yet unknown, it was clear COVID-19 would greatly affect normal university operations. By mid-March, many universities had suspended in-person classes and closed student housing, shuttered research labs, banned university sponsored travel, and asked faculty and staff to work from home. At the same time, many states instituted "stay-at-home" orders for all but essential personnel, leaving schools and childcare centers closed. Faced with these new employment conditions, and in many cases vastly increased caregiving demands, faculty adjusted their day-to-day work routines and began to express concerns about future career ramifications. Given the rigid timelines and up-or-out nature of faculty careers, a downturn in publications or decline in teaching evaluations can be potentially problematic in faculty evaluation and the promotion and tenure processes. As the full scope of the pandemic emerged, including the likely need to keep campus operations curtailed for months, it became clear that faculty would be affected across all three core elements of their professional workload: research, teaching, and service. Below we briefly sketch only some of the ways in which research, teaching, and service work may have shifted during the pandemic.

Research With campus operations severely curtailed at many universities, faculty felt an immediate impact on their research. Labs were closed, slowing or stopping research work, and in some cases leading to the loss of research material. Other faculty lost access to field work sites, archives, research collections, and human subjects. Financial impacts at universities and granting agencies meant that book contracts were delayed or cancelled, granting agencies changed priority areas, and grant funding opportunities declined. Professional associations cancelled or delayed conferences. Invited talks, symposia, and fellowships were also cancelled or delayed. Curtailed international travel meant graduate students and post-docs that were expected in labs were unable to join their research groups. Finally, caregiver needs and other workload priorities may have encroached into research time.

Teaching In response to the pandemic there were immediate shifts in teaching responsibilities and the associated workload. Faculty found themselves rapidly moving to online instruction in the middle of the semester [1]. The continued use of online education in the 2020-2021 academic year meant faculty not only had to finish out the spring 2020 semester online but had to invest additional time in learning new pedagogy and technology in order to significantly revise their courses to be delivered entirely in an online format. This was particularly challenging for courses involving labs, clinical work, studio work, or community engagement. A subset of students (and parents) expressed strong dissatisfaction with online learning, leading to lower-than-average student evaluations of teaching across many courses. Additionally, some universities assigned faculty increased teaching workloads, either due to hiring freezes, the need to replace faculty who become ill, or cutbacks in contracts for adjunct and part-time instructional faculty. As with research, caregiver needs and other workload priorities may have encroached into teaching time.

Service A final area in which the pandemic affected faculty work is service. External service, or service to the profession, was curtailed by the cancellation or delay of academic conferences, professional meetings, and grant review panels. Community based service was also impacted, with organizations temporarily shuttering or minimizing operations. In some cases faculty 
service load increased, due in part to more student contact (albeit virtual) with regard to advising and mentoring. Faculty serving on curriculum committees or faculty governance roles may have also seen increases to service demands associated with pandemic response decision making. Finally, caregiver needs and other workload priorities may have encroached into service time.

\section{Amplified Inequities}

While nearly all faculty likely experienced changes in their working conditions related to the pandemic, existing research on gender and racial inequity in faculty career attainment suggests the pandemic may uniquely affect women faculty and faculty of color, possibly amplifying longstanding inequities in career progression [2]-[5]. Broader research on gender and racial inequities in faculty careers has documented a range of outcomes. When considering scholarly work, studies show both gender and racial disparities in grant funding [6] and peer review [7]. Teaching and service are also of concern, with gender and racial bias in student evaluations of teaching [8] as well as higher teaching and service loads for women and faculty of color [9], [10], [11], [12]. Finally, studies have documented gender and racial disparities in the promotion and tenure process itself [13].

For parents, and particularly parents of young children, the childcare disruptions associated with the pandemic have had a measurable impact on productivity. During the first three months of the pandemic, STEM faculty with young children reported fewer work hours as compared to peers, while also reporting submitting fewer first author articles as compared to the three months prior to the pandemic [14]. Women are likely shouldering the brunt of this additional caregiving, as male faculty are more likely than their female peers to have a stay-at-home spouse [15]. Research on faculty time use has found while male and female faculty report similar hours spent towards professional work, mothers of young children report less time devoted to research and more time spent on caregiving and housework [16].

Initial findings on impacts of the pandemic on scholarship suggest women faculty's productivity has not kept pace with that of their male colleagues, both in STEM fields and more broadly [17]. While specific outcomes vary somewhat by discipline, the overall pattern suggests women are submitting fewer articles than in the past, even as male scholars have seen a boost in productivity over the course of the pandemic [18]. Research on scholarly preprints in STEM fields finds a growing gender gap in the prestigious, last authorship position during the early months of the pandemic [19].

Faculty of color are notably at risk for both personal and professional impacts during the pandemic. Preexisting health conditions, inequality in access to healthcare, and a higher proportion of front-line workers of color, have led to higher rates of COVID-19 among minority populations in the United States. Attention to systemic racism, including Black Lives Matter (BLM) protests, occurred during the spring and summer of 2020, leading faculty of color to report additional informal service work in caring for student wellbeing and providing mentoring and social supports. The broader social context of the 2020-2021 academic year, with efforts to address persistent racial inequality and police violence, as well as political turmoil, may have particularly affected faculty of color. For Asian faculty, the COVID-19 pandemic has led to increased experiences of racism [20]. 


\section{Initial Approach at UD}

Our approach to ensuring all faculty will be reviewed and evaluated in a way that accounts for the impacts of the pandemic began with the recommendation and subsequent adoption of new formal policies for faculty evaluation. We first discuss the process of crafting and adopting new policies, before elaborating the next steps in our policy implementation, the development of resources and workshops for faculty and those involved in the appraisal and review process.

New Policies In response to the pandemic and confirmed cases of COVID-19 on campus, the university took steps mid-March 2020 to mitigate the spread through closing student housing, moving classes to online delivery, restricting on-campus research, suspending travel, and implementing a work-from-home policy for faculty and staff. In response to these changes, the provost announced provisionary changes to faculty policies for appraisal, as well as promotion and tenure (P\&T). However, our institution has a strong history of faculty governance and our faculty is unionized. Thus, all changes to faculty personnel policies must be voted on and approved by the faculty senate, and those concerning elements of the collective bargaining agreements must be approved by the faculty union.

In the summer of 2020, the provost launched a task force charged with formulating recommendations about how to best ensure that faculty reviews could be done without bias and could properly account for disruptions caused by the COVID-19 pandemic. The task force was chaired by the Vice Provost for Faculty Affairs, and included members with administrative roles (dean, department chair), those with leadership roles in faculty governance (faculty senate and union), faculty working on faculty development and diversity work (NSF ADVANCE-IT and a local faculty accountability/peer mentoring program), and HR representation. The task force met biweekly and was charged with presenting a report to the provost and faculty senate early fall 2020. The taskforce worked to review emerging research on faculty career impacts of the pandemic, assess how other academic institutions were reacting, and develop a report with formal recommendations on how to proceed. The report hinged around four main policy recommendations, outlined below.

The first recommendation from the task force was to offer a tenure clock or contract clock extension for all full-time faculty. Given the known impacts of the pandemic on research, teaching, and service obligations, the option to allow faculty an additional year was quickly met with unanimous support from the task force. However, the details of how to best implement the policy took careful consideration. The first choice was to intentionally make the policy applicable to all full-time faculty. UD faculty includes both tenure-track and tenured faculty (T/TT), as well as non-tenure track (NTT) faculty. These NTT faculty have full-time, renewable, non-tenure track positions, which ASEE has referred to as "professional track." Many of the NTT faculty have teaching intensive workloads, which meant the pandemic and switch to online education was particularly impactful. Beyond being inclusive of T/TT and NTT faculty, the next choice was to make the tenure and contract clock extensions automatic. The policy would thus automatically cover all faculty unless they chose to opt out by notifying their chair of their intent to proceed on their normal timeline. The task force chose the opt-out option in order to encourage faculty to make use of the policy and potentially reduce any perceived stigma in requesting the extra year. 
The second recommendation from the task force was related to the use of student evaluations of teaching in peer review and tenure and promotion processes. Given the abrupt switch to online education in spring 2020, as well as continued virtual delivery of most classes in the 2020-2021 academic year, task force members were concerned that traditional course evaluation metrics and student feedback would reflect student dissatisfaction with online education, rather than summative feedback as to teaching quality. This concern was compounded by the known bias in student evaluations of teaching, where female faculty, faculty of color, and those from other marginalized groups are disadvantaged [8], [21]. For both spring 2020 and the full 2020-2021 academic year, student course feedback is to be included in future faculty peer reviews, including tenure and promotion evaluations, only at the discretion of individual faculty members.

The third recommendation from the task force was the mandatory use of COVID-19 impact statements in dossiers for peer review, including tenure and promotion. In these statements, faculty are asked to describe any negative (or positive) impacts they have experienced as a result of the pandemic. The purpose of this statement is to allow reviewers to understand how COVID19 influenced faculty members' work, both in terms of actual workload, as well as unexpected challenges that emerged. Task force members initially differed in opinion as to whether COVID19 impact statements should be optional or required. However, once committee members shared concerns that optional statements could potentially activate bias towards those choosing to use them, the full committee agreed on the importance of making the statements mandatory.

The fourth recommendation from the task force was a statement to external evaluators about the effects of COVID-19 on faculty at UD. This statement included specific language to be used when departments solicited outside letters for promotion and tenure cases. The goals of this recommendation were to ensure external reviewers (1) understood the specific procedural adjustments made in response to the pandemic for the faculty promotion and tenure process, and (2) contextualize the effects of the pandemic on faculty productivity, including potential disproportionate effects on some faculty, particularly women and faculty of color. The statement asked external evaluators to consider the faculty's overall quality of work and impact in their field, while minimizing focus on years in position or years since Ph.D. The task force included this specific language about focusing on quality of work more so than time in rank in order to minimize any negative impacts of an additional year on the tenure or contract clock for faculty. We were particularly concerned about faculty that might have already used one or more stop-theclock years due to childbirth or adoption and might be viewed by external reviewers as not sufficiently productive based on a longer than average time in rank.

Resources for Faculty, P\&T Committees, and Department Chairs A key element in supporting faculty career advancement during and after the pandemic is providing resources to help faculty navigate the new pandemic-related promotion and tenure policies, as well as education about how these policies impact faculty evaluation processes and standards. In addition to assisting faculty as they adapt to these changes and put together their dossiers, successful implementation of new policies must incorporate education for those involved in the faculty appraisal and review process. As part of our initial pandemic response at UD, we have developed several resources for faculty, outlined below, with plans to produce additional resources and workshops for faculty and reviewers in the coming academic year. 
The first written resource for faculty is guidance on writing COVID-19 impact statements. The guidance stresses that faculty should not feel compelled to share personal information, but rather should identify specific ways in which COVID-19 influenced their work, as well as their efforts to mitigate these challenges, thus making impacts that otherwise could remain invisible salient to evaluators. Also included is a list of possible impacts on core areas of faculty work, including research, teaching, and service. While the list is not exhaustive, it is designed to help faculty brainstorm and document how the pandemic has affected their own work. Finally, the guidance on writing impact statements includes a timeline of events and related institutional responses which will be updated throughout the pandemic. The timeline was included to help both faculty candidates and reviewers reference various impacts, such as research lab closures. While COVID-19 impacts are currently fresh in the minds of faculty, over time we expect it to be more difficult to recall specific events and timing. With the pandemic affecting new faculty hired in the 2020-2021 academic year, promotion and tenure committees will likely be reviewing COVID-19 impacts for at least the next seven years.

The pandemic policies will be discussed at a number of upcoming events related to the promotion and tenure process, including panels on promotion and tenure held for faculty, and workshops on documenting teaching excellence for promotion. These policies will also be reviewed during annual workshops for promotion and tenure committees, as well as mentoring sessions for department chairs.

\section{Emergent Challenges \& Implementation Strategies}

We next discuss challenges that we encountered while developing our COVID-19 policies at UD, as well as associated strategies to aid in the successful implementation of policies in a way that promotes equity and minimizes bias. The adoption of new formal policies for the faculty promotion process was a crucial first step, but this was only the beginning of efforts to address the broader question of how to account for the pandemic's effects on faculty career progression, with a particular eye towards issues of equity. Challenges identified include working with a broad range of campus stakeholders, promoting awareness across campus, and how to best ensure the pandemic does not detract from ongoing efforts to promote faculty diversity.

Working with Campus Stakeholders While the task force provided a report and recommendations to the provost and faculty senate, the group itself did not have authority to enact policy changes. Rather, the recommendations of the task force were presented to the faculty senate during a special open hearing session, where all faculty could attend, ask questions, and offer suggestions. After this meeting, the recommendations were moved to committee, and while in committee several changes were proposed. When the recommendations came out of committee, the revised version was voted on and approved by the full faculty senate. It is important to note that the policy recommendations were drafted in the summer of 2020 and not formally approved until February 2021. Thus, it took nearly a year for provisional policies first announced in March 2020 to be revised, debated, and adopted.

All four resolutions proposed by the task force passed, however the process of being approved through the faculty senate led to subtle changes that may shape policy impacts. A key example of this comes in the fourth recommendation, a statement to external evaluators about the effects of COVID-19 on faculty at the university. As described previously, the task force recommendations 
included specific language to remind evaluators of gender and racial inequity in pandemic impacts and to encourage evaluators to minimize time in rank as a consideration in their review of candidates. Much of this language was stripped out of the final resolution, leaving a rather cut and dry statement about the factual policy changes implemented at the university related to COVID-19 and faculty careers. One possible implication of this change is that external reviewers who are not familiar with the differential impacts of the pandemic may evaluate candidates in a way that exacerbates existing disadvantages for women and faculty of color.

Promoting Awareness While we have already discussed initial efforts to promote awareness of the new policies, including the development of resources and workshops for faculty, P\&T committees, and department chairs, we have reason to believe that additional work is needed to broadly build awareness about the policies and clarify their use. As part of the initial COVID-19 task force report, we created a frequently asked questions (FAQ) document to address questions pertaining to faculty career progression in light of the new policies. However, through recent discussions with small groups of faculty, it has become clear that faculty remain anxious about their career progression and unsure of how the policies will affect them. Based on these conversations, both in small groups and one-on-one, we have learned that many questions remain with regard to the specific application of policies in individual cases. We also believe many additional questions will likely emerge in coming months as faculty begin to prepare their dossiers and P\&T committees begin reviewing cases. We have found that awareness of the new policies is also limited, with some faculty reporting clear communication from their chairs and others seemingly unaware of the specifics of the new policies.

Adapting Existing Programming Given the likely disparities in the impacts of the pandemic on faculty careers, we have begun to focus on how existing efforts towards promoting faculty diversity and equity in faculty career advancement can be adapted for the situation. Funded by an NSF ADVANCE Institutional Transformation (ADVANCE-IT) grant, we have a campus institute engaged in efforts to promote faculty diversity and promote inclusive climates on campus. This group has spearheaded efforts at adapting existing programming targeting recruiting, retaining, and promoting faculty from underrepresented groups in order to address COVID-19 impacts and build awareness of policies. This part of our response is at an early stage but is anticipated to grow over time. While the full complement of programming has yet to be adapted, ideas include: (1) adapting workshops on best practices in faculty hiring to address anticipated COVID-19 impacts on job candidates; (2) including COVID-19 policy discussions in networking and mentoring events for new faculty; (3) adapting a workshop module on minimizing bias in faculty evaluation for use with promotion and tenure committees, with a focus on COVID-19 impacts.

\section{Future Plans}

We conclude by offering guidance for how institutions can remain attentive to COVID-19 impacts on faculty careers in the coming years. While the initial work of shaping policy response has likely occurred, or is in-process, across many campuses, it remains vitally important that faculty and administrators consider the longstanding impacts of the pandemic on faculty career progression. We recommend several steps universities can take to monitor and assess pandemic impacts on faculty career progression in the coming years, including ongoing evaluation of new policies and programming, as well as institutional research to monitor equity. 
Policy Evaluation As we have highlighted throughout our discussion of COVID-19 responses at UD, creating new policies for faculty evaluation is important, but these policies and associated programming to spread awareness and ensure robust implementation must be continually monitored for efficacy. Given that we are still experiencing the effects of the pandemic on faculty work, campus administrators should remain attentive to how faculty career progression is impacted.

One issue that has come to our attention recently is continued faculty concern over ongoing career affects. While the tenure and contract clock policy gives faculty a one-year extension, many faculty report they are still profoundly affected by COVID-19 impacts, even one year into the pandemic. Of particular concern are those junior faculty newly hired in the 2019 and 2020 academic years. With the campus shutdown and associated slowdown in facilities operations, as well as challenges in global supply chains and procurement, many of these faculty do not yet have their labs and research spaces up and running. These faculty may still be waiting for equipment to arrive or space to be renovated and find their research will be slowed not only for a year, but potentially much longer. The COVID task force is no longer active, but campus stakeholders remain attentive to the pandemic's impact on faculty careers. As an example, the ADVANCE Institute and the Diversity and Inclusion Committee of the faculty senate have collaborated to host an upcoming workshop for faculty on writing COVID impact statements. Events such as these will inform faculty of best practices, while also allowing us to monitor emergent faculty concerns. As we identify ongoing challenges to faculty career progression we may need to revisit and adapt our COVID-19 impact policies.

A second area of concern has to do with how COVID-19 impact policies will be evaluated by promotion and tenure committees. A clear concern among COVID task force members was that faculty who cite childcare and other caregiving constraints on their impact statements may prime evaluators for maternal bias [22]-[24]. While our implementation efforts and strategies to promote awareness of these policies across campus should potentially reduce explicit negative attitudes about the policies, implicit attitudes can be more difficult to shape. We will continue to monitor how committees evaluate these statements and adjust programming to meet new needs should they arise.

Institutional Research A final element of our approach moving forward is to conduct institutional research to monitor equity. This approach is facilitated through collaboration with our ADVANCE Institute and the office of Institutional Research and Effectiveness (IRE), a campus unit that provides data on faculty careers. Our ADVANCE team plans to continue to monitor indicators of faculty equity across a number of areas. The team regularly assesses gender and racial disparities in faculty hiring, promotion and tenure outcomes, years in rank, and faculty retention rates. Faculty climate survey data from 2018 provides a baseline for evaluating whether there are changes over time in whether faculty feel promotion and tenure processes are clear, or promotion and tenure decisions are free from bias. Ongoing qualitative research projects on faculty career satisfaction and faculty retention may also shed light on faculty experiences of COVID-19 career impacts.

This research was funded by NSF grant number HRD-1409472. 


\section{References}

[1] B. McMurtie, "The Coronavirus Has Pushed Courses Online. Professors Are Trying Hard to Keep Up.," Chronicle of Higher Education, Mar. 20, 2020.

[2] S. Goodwin and B. Mitchneck, "STEM Equity and Inclusion (Un)Interrupted?," Inside Higher Education, May 13, 2020.

[3] K. Myers et al., "Quantifying the Immediate Effects of the COVID-19 Pandemic on Scientists," Social Science Research Network, Rochester, NY, SSRN Scholarly Paper ID 3608302, May 2020. doi: 10.2139/ssrn.3608302.

[4] J. L. Malisch et al., "Opinion: In the wake of COVID-19, academia needs new solutions to ensure gender equity," Proc. Natl. Acad. Sci., vol. 117, no. 27, pp. 15378-15381, 2020.

[5] L. Gonzales and K. Griffin, Supporting Faculty during \& after COVID-19: Don't Let Go of Equity. Washington, D.C.: Aspire Alliance, 2020.

[6] D. K. Ginther et al., "Race, Ethnicity, and NIH Research Awards," Science, vol. 333, no. 6045, pp. 1015-1019, Aug. 2011, doi: 10.1126/science.1196783.

[7] R. Tamblyn, N. Girard, C. J. Qian, and J. Hanley, "Assessment of potential bias in research grant peer review in Canada," Can. Med. Assoc. J., vol. 190, no. 16, pp. E489-E499, Apr. 2018, doi: 10.1503/cmaj.170901.

[8] K. Chávez and K. M. W. Mitchell, "Exploring Bias in Student Evaluations: Gender, Race, and Ethnicity," PS Polit. Sci. Polit., vol. 53, no. 2, pp. 270-274, Apr. 2020, doi: $10.1017 / \mathrm{S} 1049096519001744$.

[9] W. G. Tierney and E. M. Bensimon, Promotion and tenure: Community and socialization in academe. SUNY Press, 1996.

[10] G. G. y Muhs, Y. F. Niemann, C. G. González, and A. P. Harris, Presumed Incompetent: The Intersections of Race and Class for Women in Academia. University Press of Colorado, 2012.

[11] C. M. Guarino and V. M. H. Borden, "Faculty Service Loads and Gender: Are Women Taking Care of the Academic Family?," Res. High. Educ., vol. 58, no. 6, pp. 672-694, Sep. 2017, doi: 10.1007/s11162-017-9454-2.

[12] J. Misra, J. H. Lundquist, E. Holmes, and S. Agiomavritis, "The Ivory Ceiling of Service Work," Academe, vol. 97, no. 1, pp. 22-26, 2011.

[13] K. Weisshaar, "Publish and Perish? An Assessment of Gender Gaps in Promotion to Tenure in Academia," Soc. Forces, vol. 96, no. 2, pp. 529-560, Dec. 2017, doi: $10.1093 / \mathrm{sf} / \mathrm{sox} 052$.

[14] R. A. Krukowski, R. Jagsi, and M. I. Cardel, "Academic Productivity Differences by Gender and Child Age in Science, Technology, Engineering, Mathematics, and Medicine Faculty During the COVID-19 Pandemic," J. Womens Health, vol. 30, no. 3, pp. 341-347, Mar. 2021, doi: 10.1089/jwh.2020.8710.

[15] L. L. Schiebinger, S. K. Gilmartin, and A. D. Henderson, Dual-career academic couples: what universities need to know. Stanford, CA: Clayman Institute for Gender Research, Stanford University, 2008.

[16] J. Misra, J. H. Lundquist, and A. Templer, "Gender, Work Time, and Care Responsibilities Among Faculty1," Sociol. Forum, vol. 27, no. 2, pp. 300-323, 2012, doi: 10.1111/j.1573-7861.2012.01319.x.

[17] M. Oleschuk, "Gender Equity Considerations for Tenure and Promotion during COVID19," Can. Rev. Sociol., Aug. 2020, doi: 10.1111/cars.12295. 
[18] C. Flaherty, "Early journal submission data suggest COVID-19 is tanking women's research productivity," Inside Higher Education, 212020.

[19] M. M. King and M. Frederickson, "The Pandemic Penalty: The gendered effects of COVID-19 on scientific productivity," SocArXiv, preprint, Sep. 2020. doi: $10.31235 / \mathrm{osf} . \mathrm{io} / 8 \mathrm{hp} 7 \mathrm{~m}$.

[20] E. Redden, "Scholars confront coronavirus-related racism in the classroom, in research and in community outreach," Inside Higher Education, 022020.

[21] R. J. Kreitzer and J. Sweet-Cushman, "Evaluating Student Evaluations of Teaching: a Review of Measurement and Equity Bias in SETs and Recommendations for Ethical Reform," J. Acad. Ethics, Feb. 2021, doi: 10.1007/s10805-021-09400-w.

[22] E. B. King, "The effect of bias on the advancement of working mothers: Disentangling legitimate concerns from inaccurate stereotypes as predictors of advancement in academe," Hum. Relat., vol. 61, no. 12, pp. 1677-1711, Dec. 2008, doi: 10.1177/0018726708098082.

[23] S. Benard and S. J. Correll, "Normative Discrimination and the Motherhood Penalty," Gend. Soc., vol. 24, no. 5, pp. 616-646, Oct. 2010, doi: 10.1177/0891243210383142.

[24] J. C. Williams, "The glass ceiling and the maternal wall in academia," New Dir. High. Educ., vol. 2005, no. 130, pp. 91-105, 2005, doi: 10.1002/he.181. 